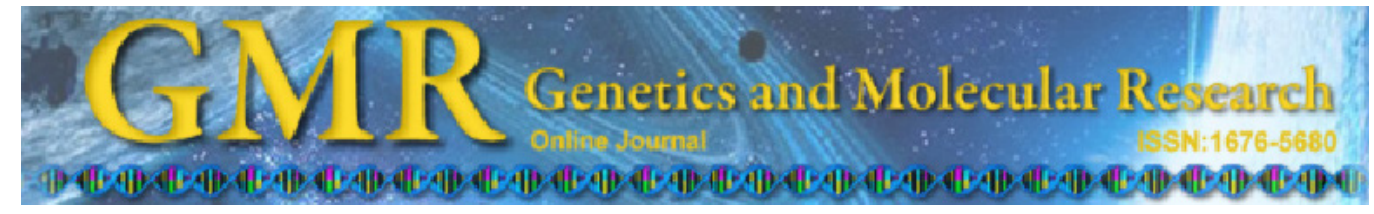

\title{
Genetic control of leaf curl in maize
}

\author{
G.C. Entringer ${ }^{1}$, F.L. Guedes ${ }^{2}$, A.A. Oliveira ${ }^{3}$, J.P. Nascimento ${ }^{3}$ and \\ J.C. Souza ${ }^{3}$
}

${ }^{1}$ Laboratório de Melhoramento Genético Vegetal, Centro de Ciências e Tecnologias Agropecuárias, Universidade Estadual do Norte Fluminense Darcy Ribeiro, Campos dos Goytacazes, RJ, Brasil

${ }^{2}$ Embrapa Caprinos e Ovinos, Sobral, CE, Brasil

${ }^{3}$ Departamento de Biologia, Universidade Federal de Lavras, Lavras, MG, Brasil

Corresponding author: J.C. Souza

E-mail: cansouza@dbi.ufla.br

Genet. Mol. Res. 13 (1): 1672-1678 (2014)

Received September 5, 2013

Accepted November 8, 2013

Published January 22, 2014

DOI http://dx.doi.org/10.4238/2014.January.22.3

ABSTRACT. Among the many implications of climatic change on agriculture, drought is expected to continue to have a major impact on agribusinesses. Leaf curling is an anatomical characteristic that might be potentially used to enhance plant tolerance to water deficit. Hence, we aimed to study the genetic control of leaf curl in maize. From 2 contrasting inbred lines for the trait, generations $\mathrm{F}_{1}, \mathrm{~F}_{2}$, and the backcrosses were obtained. All of these generations were evaluated in a randomized block design with 2 replicates. Leaf curl samples were collected from 3 leaves above the first ear at the tasseling stage, and quantified by dividing the width of the leaf blade with natural curling against its extended width. The mean and variance components were estimated by the weighted least square method. It was found that the trait studied has predominance of the additive effects, with genetic control being attributed to few genes that favor selection and exhibit minimal influence from the environment.

Key words: Zea mays L.; Genetic components; Heritability 


\section{INTRODUCTION}

Researchers throughout the world have been studying the effects of climatic change on the planet for years. Recently, various scientists from private and public companies worldwide have analyzed the data, trends, and the implications of climate change for agriculture, concluding that drought will continue to have a major impact on agribusinesses. Climatic changes are expected to influence agribusinesses in the following areas: (1) increasing food demand, (2) the scenario of global warming, if confirmed, and (3) changes in rainfall pattern. Thus, abiotic stresses are anticipated to directly affect crop development and productivity (Poland et al., 2004).

Corn is one of the most affected crops by water stress; yet, this crop has a worldwide distribution and a diversity of production and consumption uses. The greatest corn yields are associated with water consumption levels of 500 to $800 \mathrm{~mm}$ across a whole crop cycle (about 4 months). The lack of water during critical periods, such as germination, flowering, and grain filling, might reduce yields and threaten the ability of farmers to recover their investments. To overcome problem, various studies, primarily conducted by private breeding companies, have focused on identifying and transferring genes related to drought tolerance by means of genetic modification in various crops (Lata and Prasad, 2011). For instance, simple maize hybrids that produce up to $15 \%$ more yield under water stress conditions are already available in the markets.

Nevertheless, this technology still has limitations because of the quantitative characteristic of the drought tolerance trait, and because genetic modification processes focus on just one or a few genes. Alternatively, classical breeding could be used, which facilitates the simultaneous processing of thousands of genes (Ramalho et al., 2012). Ultimately, it is important to identify traits associated with drought tolerance, with some having already been proposed (Bolaños et al., 1993; Betrán et al., 2003).

It is known that water deficit reduces the leaf area of the plants through modification in the architecture of the plant canopy. To resolve this conflict, the plant develops various morpho-physiological mechanisms, such as leaf curling, which helps conserve water for use in other functions, such as seed production. Jordan (1983) observed that leaf curling causes a reduction in the effective leaf area and, consequently, in the photosynthetically active leaf extension of the plant, in addition to reducing dehydration and reducing water consumption during periods of high evaporative demand. Hence, the leaf curling characteristic might prove an efficient resource for drought tolerance.

It has been routinely observed (mainly in research fields focused on obtaining breeding lines) that may be maize plants stand out by their differentiated phenotypes. For instance, such plants have their leaf area permanently rolled, even when conditions for crop growth are ideal (Figure 1A). Therefore, such breeding lines have relevant anatomical characteristics that enable us to make inferences about their potential use as a source of germplasm for plant breeding programs, with a view toward the development of cultivars tolerant to low water availability. Nevertheless, there is a paucity of information in the scientific literature about the genetic control of this trait.

Thus, it is important to determine the genetic factors that are responsible for passing on the leaf curl trait in maize. Hence, this study aimed to elucidate the genetic control of this trait to contribute information to the genetic breeding of maize for drought tolerance characteristics. 


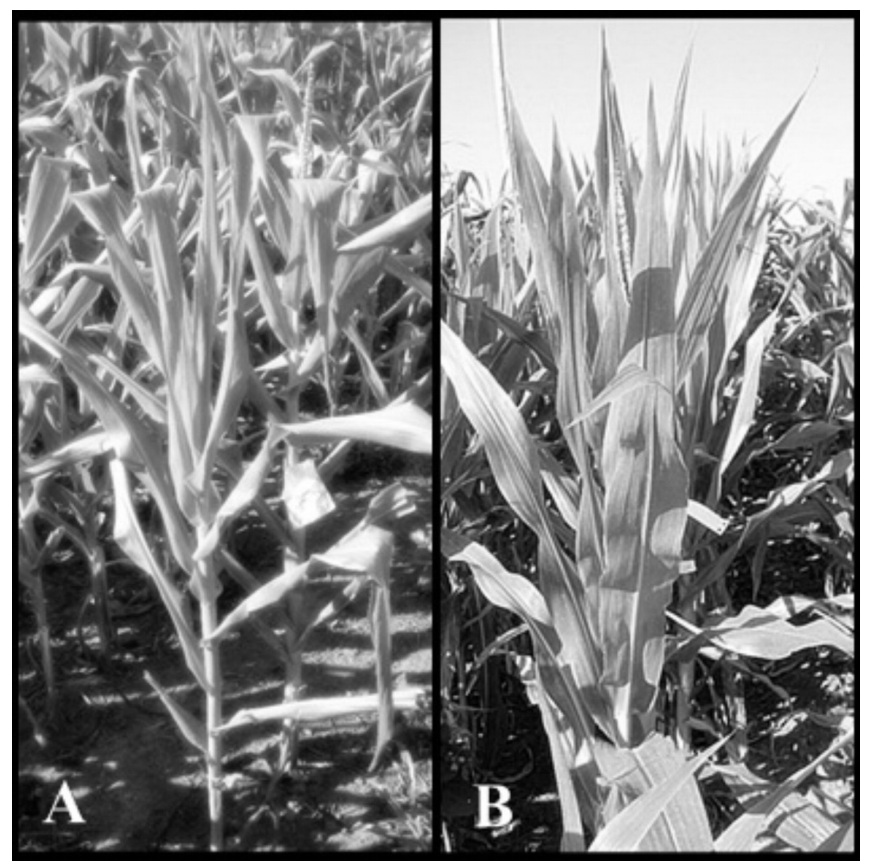

Figure 1. Maize breeding program lines from Universidade Federal de Viçosa. A. Maize line with curled leaf blade $\left(\mathrm{P}_{1}\right)$; B. maize line with normal leaf blade $\left(\mathrm{P}_{2}\right)$.

\section{MATERIAL AND METHODS}

The field trial was conducted in an experimental area located in the southern region of Minas Gerais, Brazil [21 $58^{\prime} \mathrm{S}$ latitude, $45^{\circ} 22^{\prime} \mathrm{W}$ longitude; $910 \mathrm{~m}$ altitude above sea level (asl)].

To study the genetic control of leaf curl, estimates of the genetic components were obtained by following the method proposed by Cavalli (cited in Rowe and Alexander, 1980; Mather and Jinks 1984). This method proposes the use of 2 contrasting parents for the trait. In this case, the breeding line with curled leaves (LE) was parent 1- $\mathrm{P}_{1}$ (Figure 1A) and the breeding line with normal leaves (L5) was parent 2- $\mathrm{P}_{2}$ (in Figure 1B), in addition to the $\mathrm{F}_{1}$ and $\mathrm{F}_{2}$ generations, and the backcrosses $\left(\mathrm{RC}_{11}\right.$ and $\left.\mathrm{RC}_{12}\right)$.

The parents and the segregating populations were evaluated in a randomized block design with 2 replicates. Sowing was carried out during the 2009/2010 growing season. Plots contained $5 \mathrm{~m}$ rows, with 2 rows for each parent and $\mathrm{F}_{1}$ generation, and 6 rows for the other generations. A sowing density equivalent to 66,666 plants/ha was used for all populations. In each generation, different numbers of plants were evaluated: 42 from parent $1 ; 67$ from parent 2; 62 from the $\mathrm{F}_{1}$ generation; 294 from the $\mathrm{F}_{2}$ generation; 199 from $\mathrm{RC}_{11}$; and 166 from $\mathrm{RC}_{12}$ (see Table 1 for overview).

When the plants were at the tasseling stage, also termed R1 (Fancelli and Dourado Neto, 2000), leaf samples were collected for measurement and data analysis. For each plant, a digital caliper rule (digital capiler ruler IP 54 Vonder - $200 \mathrm{~mm}$ ) was used to estimate the mean leaf curl ratio from 3 leaves sampled above the first ear. The leaf curl ratio was calculated from 
the leaf width with natural curling divided by its extended width (Figure 2). Of note, the genotypes that exhibited maximum natural curling (extreme genotypes) of the leaf blade versus totally extended leaves would produce ratios of $<0.5$ and close to 1.0 , respectively.

Table 1. Number of individuals evaluated in each population with the mean values of the leaf curl ratio and the respective variance, obtained in the 2009/2010 growing season in Lavras, MG, Brazil.

\begin{tabular}{lccc}
\hline Population & Number of plants & Mean & Variance \\
\hline $\mathrm{P}_{1}$ & 45 & 0.4407 & 0.009725 \\
$\mathrm{P}_{2}$ & 67 & 0.9714 & 0.001302 \\
$\mathrm{~F}_{1}$ & 62 & 0.6464 & 0.006503 \\
$\mathrm{~F}_{2}$ & 294 & 0.5908 & 0.020343 \\
$\mathrm{RC}_{11}$ & 199 & 0.4971 & 0.010705 \\
$\mathrm{RC}_{12}$ & 166 & 0.8094 & 0.011938 \\
\hline
\end{tabular}

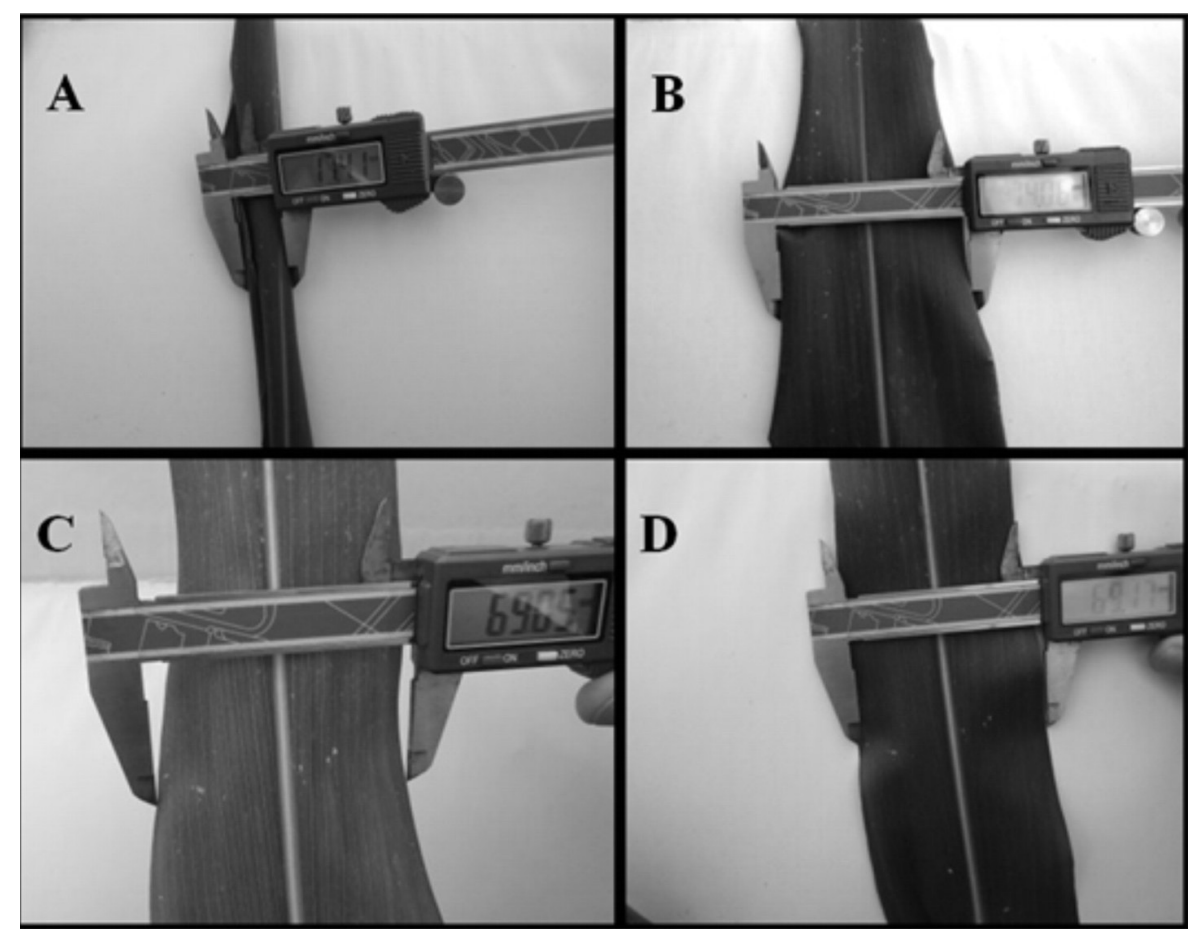

Figure 2. Measurement of the ratio of leaf curl: A. $\mathrm{P}_{1}$ with natural leaf curl; B. $\mathrm{P}_{1}$ with the leaf blade extended; C. $\mathrm{P}_{2}$ with natural leaf; $\mathbf{D}$. with the leaf blade extended.

The data obtained were submitted to analysis of variance. The mean components were estimated through the weighted least square method using the model: $\hat{\beta}=\left(C^{\prime} N S^{-1} C\right)^{-1}\left(C^{\prime} N S^{-1} Y\right)$ in which $\hat{\beta}$ is the vector of the parameters ( $\hat{m}=$ estimator of the mean; $\hat{a}=$ estimator of the deviations of the homozygote in relation to the mean; and $\hat{d}=$ estimator of the deviations of the heterozygote in relation to the mean); $C$ is the matrix of the model, containing the general mean and contribution of homozygous loci and heterozygosis loci; $N$ is the matrix of the number of plants evaluated within each generation; $S$ is the matrix of the variances associated with 
the generations; and $Y$ is the vector of the mean values observed in the generations (Ramalho et al., 2012).

The components of variance were estimated using the interactive weighted least square method, using the model: $\hat{\beta}=\left(C^{\prime} N C\right)^{-1}\left(C^{\prime} N Y\right)$, in which $\hat{\beta}$ is the vector of the parameters $\left(\hat{\sigma}_{A}^{2}\right.$ $=$ estimate of the additive genetic variance; $\hat{\sigma}_{D}^{2}=$ estimate of the dominance genetic variance; and $\hat{\sigma}_{E}^{2}=$ estimate of the environmental variance); $C$ is the matrix of the model, consisting of the additive, dominant, and environmental variance within each generation; $N$ is the matrix of the degrees of freedom associated with each population; and $Y$ is the vector of the variances observed within each population (Ramalho et al., 2012). All of the estimates were obtained using the Mapgen software (Ferreira and Zambalde, 1997).

Estimates of heritability were obtained in the restricted sense $\left(\hat{h}_{r}^{2}\right)$, using the expression described by Ramalho et al. (2012).

\section{RESULTS AND DISCUSSION}

The breeding lines proved to be contrasting for the leaf curl trait, exhibiting different proportions of leaf curl; specifically, the parents $\mathrm{P}_{1}$ and $\mathrm{P}_{2}$ had phenotypic mean values of $<0.5$ and 1.0, respectively (Table 1). Cruz et al. (2001) stated that this contrast is vital for obtaining greater precision in genetic analyses.

Figure 3 shows that the mean of the $\mathrm{F}_{1}$ generation was similar to that of the $\mathrm{F}_{2}$ generation, and were intermediate in relation to leaf curl. This observation indicates that, in principal, the involved genes must have predominantly additive allelic interactions. The backcrosses performed as expected. When the $\mathrm{P}_{1}$ parent was used recurrently, the mean of the $\mathrm{RC}$ shifted towards maximum curling values, whereas when the $\mathrm{P}_{2}$ parent was used recurrently, the mean of the RC shifted towards maximum leaf blade extension values. Estimates of the variances were consistent with that expected, in which the $\mathrm{F}_{2}$ generation exhibited the greatest variance (Table 1).

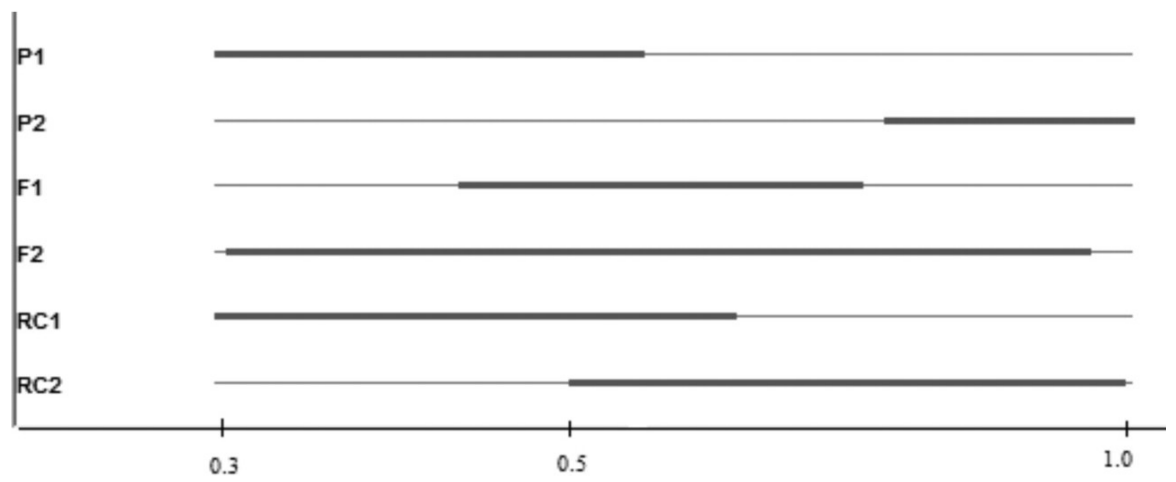

Figure 3. Distribution of the ratio of leaf curl within each generation evaluated.

Estimates of the genetic parameters are presented in Table 2, and were based on the means of the generations. The estimates were obtained using the model composed of the parameters $\hat{m}$, $\hat{a}$, and $\hat{d}$. Of note, this dominant additive model, without epistasis, was sufficient for explaining more than 0.99 of the variation of the data; in other words, the observed mean values did not differ from the estimated mean values, as shown by the $X^{2}$ and $R^{2}$. 
Table 2. Joint-scaling test for the leaf curl trait in maize involving the parameters $m, a$, and $d$, and the value of the $\mathrm{R}^{2}$ and $\mathrm{X}^{2}$.

\begin{tabular}{lccc}
\hline Parameters & Estimate & Standard error & Prob $>|\mathrm{t}|$ \\
\hline$M$ & 0.6795 & \pm 0.029 & 0.0002 \\
$A$ & -0.2903 & \pm 0.029 & 0.002 \\
$D$ & -0.066 & \pm 0.057 & 0.3334 \\
$X^{2}$ & $66.16^{\mathrm{NS}}$ & & \\
$R^{2}$ & 0.998 & & \\
\hline
\end{tabular}

Not significant at 0.05 .

Of the 3 mean components, only the parameters $\hat{m}$ and $\hat{a}$ differed from 0 , indicating the absence of dominance in the control of the trait (Table 2). The negative estimate of $\hat{a}$ indicates that the additive effect moves in the direction of conferring lower values to the expression of the trait; in other words, the greater the expression of leaf curl, the lower the value observed.

Estimates of the components of variance are presented in Table 3. Again, the adopted model explained more than 0.99 of the variation of the leaf curl, as shown by the coefficient of determination $\left(R^{2}\right)$. This high adjustment of $R^{2}$ observed in both models, for both the mean and variance components, allow us to infer that the trait is not under complex genetic control.

$\begin{aligned} & \text { Table 3. Estimates of the components of variance and their respective standard errors, } \mathrm{R}^{2}(\%) \text {, and heritability in } \\
& \text { the restricted sense obtained for the leaf curl trait. }\end{aligned}$
\begin{tabular}{lcc}
\hline Parameters & Estimate & Standard error \\
\hline$\sigma^{2}$ & 0.0288 & \pm 0.021 \\
$\sigma^{2}$ & -0.0137 & \pm 0.011 \\
${ }_{D}{ }^{2}$ & 0.0053 & \pm 0.003 \\
$\hat{h}_{r}^{2}$ & 0.84 & \\
$\mathrm{R}^{2}$ & 0.9999 & \\
\hline It may be observed that the estimate of dominance variance did not differ from zero,
\end{tabular}

This result corroborates that obtained for the mean components; in other words, additive variance predominates in the expression of the trait. This result is of fundamental importance for breeding programs, as traits with additive genetic control are desirable, because of facilitated selection and the possibility of transferring favorable alleles to the genotypes of interest.

Heritability represents another parameter that provides information about the genetic control of the trait, and allows us to infer whether the trait is easily selected for; more specifically, heritability in the restricted sense $\left(\hat{h}_{r}^{2}\right)$. In the present study, $\hat{h}_{r}^{2}$ was high $(84 \%)$. In this case, $\hat{h}_{r}^{2}$ only represents additive genetic variance that is associated with the reproductive value (Table 3). Other traits suggested for the selection of genotypes tolerant to drought have low heritability (Bolaños et al., 1993)

In corroboration with the stated indices in this study, estimates of the number of genes indicate that leaf curl is controlled by a few genes. Therefore, selection for this trait is possible, despite the scarcity of reports about the genetic components for this trait in the published literature.

Leaf curl is associated with morpho-physiological changes of plants subject to condition of water stress. Hence, the genotypes that exhibit this trait are genetically controlled, and might potentially be used as a source of alleles for genetic breeding drought tolerant cultivars. 


\section{CONCLUSIONS}

Estimates of mean and variance components showed that the additive effect predominates in relation to dominance effects, characterizing additive allelic interaction. Leaf curl control is attributed to just 1 to 2 genes, making it an easy trait to select for. The leaf curl trait is highly heritable, because it is minimally influenced by the environment.

\section{ACKNOWLEDGMENTS}

The authors thank the Conselho Nacional de Desenvolvimento Científico e Tecnológico.

\section{REFERENCES}

Betrán FJ, Ribaut JM, Beck D and Gonzalez de León D (2003). Genetic diversity, specific combining ability and heterosis in tropical maize under stress and nonstress environments. Crop Sci. 43: 797-806.

Bolaños J, Edmeades GO and Martinez L (1993). Eight cycles of selection for drought tolerance in tropical maize. III. Responses in drought-adaptive physiological and morphological traits. Field Crops Res. 31: 269-286.

Cruz CD, Regazzi AJ and Carneiro PCS (2001). Modelos Biométricos Aplicados ao Melhoramento Genétic. 2nd edn. UFV, Viçosa.

Fancelli AL and Dourado Neto D (2000). Ecofisiologia e Fenologia. In: Produção de milho (Fancelli AL and Dourado Neto D, eds.). Agropecuária, Guaíba, 21-54.

Ferreira DF and Zambalde AL (1997). Simplificação das Análises de Algumas Técnicas Especiais da Experimentação Agropecuária no Mapgen e Softwares Correlatos. In: Congresso da Sociedade Brasileira de Informática Aplicada a Agropecuária e Agroindústria, 2 UFMG, Belo Horizonte, 285-291.

Jordan WR (1983). Whole Plant Response to Water Deficit: an Overview. In: Limitations to efficient water use in crop production (Taylor HM, ed.). Madison: ASA; CSSA; SSA, 289-317.

Lata C and Prasad M (2011). Role of DREBs in regulation of abiotic stress responses in plants. J. Exp. Bot. 62: 4731-4748.

Mather K and Jinks LL (1984). Introdução à Genética Biométrica. Sociedade Brasileira de Genética, Ribeirão Preto.

Poland D, Sawkins M, Ribaut JM and Hoisington D (2004). Resilient Crops for Water Limited Environments: Proceedings of a Workshop Held at Cuernavaca. CIMMYT, Mexico, DF.

Ramalho MAP, Santos JB dos and Pinto CAB (2012). Genética na Agropecuária. 4th edn. UFLA, Lavras.

Rowe KE and Alexander WL (1980). Computations for estimating the genetic parameters in joint-scaling test. Crop Sci. 20: $109-110$. 